\title{
ANTROPOLOGIA DA RELIGIÃO - \\ Entendendo a possessão espiritual e o transe baseado em estudo de casos
}

ENTREVISTA: Bettina E. Schmidt

\author{
Alethea Aires Pecora* \\ Cristina Angelini Melchior**
}

No momento da entrevista, a Dra.Bettina Schmidt estava alocada como pesquisadora em Estudos das Religiōes na Universidade de Bangor, Escola de Teologia e Estudos Religiosos ${ }^{1}$. Seu mestrado foi em Antropologia e Estudos Religiosos e sua tese foi sobre a medicina tradicional da Purhépecha, no México; o doutorado com tese sobre etnicidade e religião, com referências à Santeria e ao Espiritismo em Porto Rico. O pós-doutorado foi em teorias culturais e religiōes caribenhas, todos pela Universidade de Marburg. Bettina tem trabalhado como conferencista em Antropologia para várias universidades alemãs. Foi professora convidada na Universidade de Nova York e na Universidade Nacional de San Antonio Abade em Cusco, no Peru. No momento, ela é membro do conselho dos editores da revista Indiana, publicação anual do Instituto Ibero-americano em Berlim, e da revista Curare, de Antropologia Médica e Psiquiatria Transcultural, publicada pela AG Ethnomedicine. Recentemente, Bettina transferiu-se para a Universidade de Wales Trinity Saint David, no país de Gales. O departamento em que atua combina Teologia, Estudos das Religiōes e Estudos Islâmicos, e reúne dezenove pesquisadores com diferentes especializações. Em 2010, a pesquisadora publicou o livro Spirit Possession and Trance: New Interdisciplinary Perspectives (Continuum Advances in Religious Studies Series) (Londres, Continuum).

REVER: Bettina, fale um pouco do seu trabalho e por que escolheu viver e trabalhar fora da Alemanha.

BES: Após o término do meu pós-doutorado, devido à dificuldade de encontrar uma oportunidade nas universidades da Alemanha, eu me candidatei a uma vaga na Universidade de Oxford para o departamento de Estudos Religiosos

\footnotetext{
* Mestranda em Ciências da Religião pela Pontifícia Universidade Católica de São Paulo

"Mestre em Ciências da Religião pela Pontifícia Universidade Católica de São Paulo.

${ }^{1}$ Atualmente (2011): University of Wales Trinity Saint David - School of Theology, Religious Studies and Islamic Studies.
} 
186 Alethea Aires Pecora e Cristina Angelini Melchior

e Antropologia. De início, eu achava que não teria chances porque era a única candidata estrangeira. No entanto, isso não parece ter sido um impedimento, uma vez que fui convocada e contratada por três anos. Para mim, estar num ambiente de língua inglesa e, particularmente, em Oxford, foi uma grande oportunidade profissional para sair do sistema alemão. Anteriormente, eu já havia feito pesquisas e ministrado aulas nos Estados Unidos, mas sempre acabava retornando para a Alemanha. Graças a essa experiência em Oxford, fui contratada pela Universidade de Bangor, afiliada à Universidade de Marburg, na Alemanha. Trabalho com religião afrocaribenha há 20 anos, comecei em 1990. Fui pela primeira vez a Porto Rico quando decidi fazer meu doutorado sobre os caribenhos. Durante minha visita, decidi trabalhar com as religiōes. Desde então, estudo as religiōes afrocaribenhas analisando diferentes áreas e questōes, mas geralmente questōes sobre a identidade, imigração e diáspora. Foi então que observei algumas possessōes espirituais pela primeira vez e decidi escrever um pequeno artigo sobre o assunto, focando os praticantes e sua performance, enfatizando o quanto isso era fascinante. Então, quando voltei para a Inglaterra, percebi que não era hora de entrar na questão de possessões espirituais, porque eu teria que me aprofundar mais sobre o assunto. Em Oxford comecei a estudar a possessão na África e a história europeia da possessão espiritual. Foucault escreveu sobre isso, muitos pensadores franceses trataram do assunto. Eu decidi delimitar meu campo. Então, como antropóloga, percebi a necessidade de entrar no campo empírico, não só no campo teórico. Decidi mostrar para outras pessoas no que eu estava trabalhando.

\section{REVER: Como você vê a situação da Antropologia na Inglaterra e na Europa em geral?}

BES: Por muito tempo a França e a Alemanha seguiram uma Antropologia Cultural, enquanto a Escandinávia e o Reino Unido seguiam mais o caminho da Antropologia Social. Hoje, essa delimitação já não existe e tanto a Inglaterra quanto os outros países europeus dedicam-se às duas áreas da Antropologia. Agora, as duas correntes antropológicas são capazes de tratar de religião e conceitos culturais, diferentemente de antes, quando o foco estava nas hierarquias sociais e políticas. Recentemente a Europa tem se dedicado mais aos estudos antropológicos que seguem a linha de pesquisa norte-americana, e eu vejo isso com pesar. A França tem tradiçôes maravilhosas, assim como o Reino Unido. E, antes, eles tinham orgulho dessas tradições. Da minha parte, não sei se isso é um bom desenvolvimento, eu sempre tento me aproximar e trabalhar mais com as ideias da América Latina. Nas minhas publicações sempre cito estudiosos e pesquisadores da universidade da Cidade do México e das universidades brasileiras para mostrar que a Antropologia é uma tradição de destaque na América Latina e não somente nos Estados Unidos. Entretanto, esse tipo de estudo não é tão apreciado em todas 
as partes da Europa, pois há uma tendência enorme em se voltar somente para o que está acontecendo nos Estados Unidos.

REVER: Como você vê a relação entre as áreas da Antropologia e da Ciência da Religião?

BES: A Inglaterra não adota a mesma terminologia da Alemanha e do Brasil. Lá não se fala Ciência ou Ciências da Religião e sim Estudos Religiosos. Uma vez que a Antropologia estuda a cultura e a identidade de um povo, ou seja, aquilo que as pessoas fazem, resolvi me dedicar tanto à Antropologia quanto às Ciências da Religião. Isto porque acredito que não podemos entender o que as pessoas fazem se nós não compreendermos primeiro aquilo em que elas acreditam. Esta é minha abordagem da religião: compreender o outro através do seu sistema de crenças. É claro que nas Ciências da Religião se utilizam diferentes métodos: as pessoas analisam textos, estudam as línguas, interpretam textos antigos em sânscrito, em aramaico, realizam estudos bíblicos. Outras, ainda, olham através da Sociologia, das dinâmicas sociais. Entretanto, mais e mais pessoas procuram por métodos usados por décadas na Antropologia, daí eu pensar que a Antropologia e as Ciências da Religião têm uma forte relação. Claro que, quando ensino Ciências da Religião, não fico só na Antropologia, mas menciono os outros campos das Ciências da Religião, justamente para mostrar essa diversidade, tudo o que tem impacto na religiosidade. Mas, como sou antropóloga, é claro que levo mais para o meu campo.

REVER: No seu artigo em "O espectro disciplinar da Ciência da Religiäo", seu público-alvo era o leitor brasileiro. Caso seu artigo fosse endereçado ao leitor europeu, sua abordagem teria sido diferente?

BES: Eu publiquei recentemente um texto didático de Antropologia da Religião para os estudantes alemães. Parte dele foi similar ao artigo - eu usei a mesma estrutura -, mas é claro que também incluí muito mais sobre o desenvolvimento alemão, o desenvolvimento europeu e também autores que não mencionei nesse artigo do Brasil. No livro, eu tive oportunidade de escrever muito mais. Incluí autores brasileiros, de maneira a mostrar o que acontece em outras regióes. Ao final de cada capítulo incluí uma lista de recomendações bibliográficas, mencionando autores brasileiros e o desenvolvimento da Antropologia no Brasil.

REVER: Como você avalia a sua área, Antropologia, nos estudos atuais sobre a religiosidade no Brasil?

BES: Eu penso que no Brasil a Antropologia da Religião é relativamente forte. Conheci diversas pessoas que trabalham em Antropologia da Religião em 
188 Alethea Aires Pecora e Cristina Angelini Melchior

Florianópolis e Porto Alegre, desenvolvendo uma Antropologia mais sociológica como nos movimentos pentecostais brasileiros, mostrando a importância desse campo nas universidades no Brasil. Acredito que isso se deva à forte influência da herança francesa, já que Strauss e Bastide estudaram religião, o que justifica a continuação dessa tradição no Brasil. Isto para mim é bom porque é difícil ter informaçōes na Europa sobre as publicações brasileiras. Estou compilando todas as informaçôes para levar para casa.

\section{REVER: Do que trata a sua pesquisa, quais os seus objetivos?}

BES: Há cerca de dois anos, organizei uma conferência sobre a interpretação da possessão espiritual e do transe, reunindo pessoas que trabalham com este tema. Depois nos utilizamos dessas comunicações para realizar uma conferência internacional na minha universidade, Bangor. Dessa conferência resultou um livro. Em artigos, procuro escrever sob um ponto de vista mais teórico, tentando unir o relato pessoal da prática com a teoria existente sobre o assunto. Eu quero obter informaçôes sobre a dinâmica desse conceito e o ponto de vista dos crentes, porque a interpretação da possessão espiritual vem do ponto de vista ético. Tenho tentado coletar informaçôes dos praticantes para entender de dentro aquilo em que eles acreditam, o que eles sentem. Eu penso que essa prática é enormemente importante para o nosso estudo das Ciências da Religião porque é um fenômeno que acontece no mundo inteiro, e não está restrito somente a um contexto cristão, mas em todas as religiōes aparecem alguns aspectos do transe espiritual. Às vezes esses aspectos são tidos como uma manifestação mais demoníaca, em outros, são vistos como divinos. Mas estão no mundo inteiro, em diferentes religiões e culturas. Eu acho que esse, no fundo, é o ponto central de algumas experiências religiosas.

\section{REVER: Como é desenvolver uma pesquisa de campo em uma sociedade à qual não} se pertence?

BES: Temos na tradição da Antropologia europeia sempre essa regulamentação não oficial de que o trabalho de campo tem que ser feito em diferentes contextos, no contexto exterior, para experimentar a visão do outro. Um dos debates nos anos 1990 na Antropologia era de que não poderíamos encontrar o outro em nossa própria terra natal. Estudantes, para se iniciarem em Antropologia, tinham que viver fora do seu contexto, sozinhos, fora do país. Isso vem mudando nas últimas décadas, porque agora um estudante pode fazer seu trabalho de campo em grandes cidades. Eu fiz meu pós-doutorado em Nova York, que é um ambiente diferente de uma pequena vila no México, onde fiz minha primeira pesquisa. Agora, a Antropologia feita dentro de casa também é possível. Às vezes, pesquisando pessoas que moram nas ruas da sua própria cidade, você pode identificar o outro, 
porque você pode ter uma distância social maior desse indivíduo do que de um indivíduo que vive na Europa, ou seja, distante de você. O trabalho de campo, para mim, é inspirador.

REVER: Diferentemente de se trabalhar com povos tribais, como é trabalhar com grandes sociedades como São Paulo?

BES: No México eu precisava de uma conexão familiar, eu morei na casa de uma família e pertencia a esta família. Percebi mais tarde que essa família tinha problemas com outras famílias dessa mesma vila, por isso eu não era aceita pela comunidade. Isso significa que nas sociedades tribais sua posição dentro dessa comunidade abre ou fecha as portas de comunicação. E claro, em outros ambientes, isso é diferente. O mais difícil algumas vezes, nas áreas urbanas, é conseguir informação sobre as cerimônias, o local onde vão acontecer. Na vila todo mundo sabe de tudo. São os altos e baixos na pesquisa de um e de outro.

\section{REVER: Por que para a sua pesquisa você escolheu a cidade de São Paulo?}

BES: Eu gosto de São Paulo desde quando vim pela primeira vez, alguns anos atrás. Provavelmente porque fui bem recebida e alguns estudantes me apresentaram a cidade. Eu também achei São Paulo semelhante a Nova York. Antes, já tinha ido para Salvador, que também é um centro urbano interessante, mas é muito mais restrito para minha pesquisa, pois lá predomina o Candomblé. Em São Paulo coexistem diversas tradições religiosas. E porque eu queria investigar as diferenças existentes entre essas manifestações, penso que São Paulo tenha sido uma boa escolha.

\section{REVER: Qual a relevância do povo brasileiro para a sua pesquisa de campo?}

BES: O suporte do povo brasileiro faz com que a pesquisa seja possível. Eu também tive boas experiências com os brasileiros porque eles gostam de falar sobre religião. Em Nova York há um controle maior ao se falar de religião porque muitas das práticas são ilegais, então, normalmente, eles não gostam de falar com uma pessoa estranha sobre suas práticas. Mas aqui as pessoas são mais abertas e isso tem a ver com o modo brasileiro de ser. E, para mim e para a pesquisa, isso é maravilhoso.

REVER: Quais as contribuiçôes eventuais que os resultados das suas pesquisas poderão oferecer para o campo cientifico das religiōes?

BES: Eu espero desenvolver uma nova forma de entendimento sobre a possessão espiritual e o transe. Eu não quero associar isso a doenças mentais. Quero atingir o público em geral, e fazer com que esse estudo não fique restrito ao campo 
190 Alethea Aires Pecora e Cristina Angelini Melchior

acadêmico, desenvolvendo um novo modo de compreensão da possessão. No ano passado eu falei em uma conferência dirigida a pessoas que tratam de doenças mentais para dizer a elas que a possessão espiritual não está relacionada à saúde mental. E quero continuar a fazer isso. Espero trazer uma contribuição não só para adicionar uma outra história sobre o Brasil, mas também para mostrar como isso se encaixa no debate geral sobre a possessão em diversos países.

REVER: Quais os aspectos positivos e negativos que você aponta ao se realizar uma pesquisa de campo no Brasil?

BES: A primeira dificuldade é obter a informação. Às vezes, leva-se muito tempo para obter informaçôes sobre as cerimônias, onde elas acontecem, conseguir que as pessoas envolvidas concordem em dar entrevistas. No começo elas dizem que sim, são amigáveis, sem problemas; mas então as pessoas viajam, não atendem, não respondem. Eu acho que o problema é que o brasileiro se compromete e depois não cumpre. Eu não tenho muito tempo, não posso esperar até o Natal para ter as respostas. Outro problema em fazer pesquisas em São Paulo é o tráfego, o problema de locomoção. Um aspecto positivo é que a maioria das cerimônias é aberta. Eu posso comparecer, sou convidada a participar porque eles não têm medo uma vez que não fazem nada ilegal.

REVER: Como você avalia a sua pesquisa até aqui? De uma forma geral o trabalho de campo em São Paulo foi o que você esperava?

BES: Até agora tenho 23 entrevistas gravadas, o que é representativo para uma antropóloga. Além das entrevistas, tenho todo o material pesquisado em bibliotecas e sites aqui no Brasil que vou levar de volta para casa. Nesse aspecto, o estar em São Paulo preenche minhas expectativas. Continuo não vendo um resultado final, até este ponto não cheguei a uma conclusão. Preciso mais tempo para compilar os dados e discutir o resultado com outras pessoas da área. Volto para casa com a ideia de escrever um livro.

\section{REVER: Como pesquisadora, as questōes de Gênero influenciam na sua pesquisa?}

BES: No Equador, por exemplo, eu visitei uma vila na qual eu queria fazer a pesquisa sobre diferentes religióes. Primeiro, eu tinha que me apresentar e conseguir permissão para fazer a entrevista. Em uma das vilas que fui, um jovem estudante mostrou-me o caminho da vila e me acompanhou na entrevista. Quando fui entrevistar o ancião, ele respondia para o estudante e não para mim, embora eu fizesse as questôes. Isto é típico de algumas sociedades tradicionais nas quais as mulheres são simplesmente ignoradas. O homem só se dirige ao homem, eles só confiam nos homens. Frequentemente as pessoas se organizam dessa maneira. No Brasil, um pai de santo, talvez por medo, não se sentiu confortável em falar 
comigo sozinho. Em duas ou três vezes ele se dirigiu ao estudante que me apresentou a ele, que era homem, mas eu o interrompi de uma forma polida para dizer que a entrevista era minha. Às vezes isso acontece, mas não é frequente. Aqui no Brasil esse tipo de situação é um pouco melhor. A parte negativa é que às vezes as cerimônias têm uma longa duração e a dificuldade é o transporte público - pelo fato de eu ser mulher e de os cultos acabarem tarde.

REVER: Com quais religioes você trabalha? Assinale as diferenças que você percebe entre elas.

BES: Há grandes diferenças entre as três tradiçôes religiosas com as quais eu trabalho: Umbanda, Candomblé e o Centro Espírita. É claro que, às vezes, elas se misturam. Pessoas que tenho entrevistado frequentam o Candomblé e a Umbanda ao mesmo tempo, mas, normalmente, estão divididas. Diferentes hierarquias, cerimônias, mesmo a possessão espiritual é diferente. Algumas estruturas e funções, no entanto, são idênticas, o conteúdo da prática é que difere. Os orixás, por exemplo, são diferentes. Eles se apresentam de forma diferente no Candomblé e na Umbanda. Já o Espiritismo é uma mistura. A Umbanda é uma mistura, claro. Mas um recebe a influência do outro.

REVER: Como você pretende superar as barreiras impostas pela comunicação, no caso, as questôes das traduçôes e do entendimento de uma cultura estrangeira?

BES: Eu gravo as entrevistas procurando não interromper a pessoa no momento em que ela está dando seu depoimento. Não quero interromper o fluxo. Dessa forma, se eu não entendo o que a pessoa fala, posso recorrer a terceiros para me auxiliar na tradução. Minha experiência aqui em São Paulo é que as pessoas estão abertas a diferentes sotaques e ao meu "portunhol". Fora de São Paulo as pessoas têm mais dificuldade, pois não estão acostumadas com quem fala espanhol. Em Porto Alegre é diferente porque eles estão mais próximos da fronteira. Depende de cada pessoa. Às vezes eles não têm problema nenhum em me compreender e tentam explicar de diferentes maneiras para que eu possa compreender. Eu também procuro nas literaturas específicas de outras tradições religiosas para conferir nos glossários os termos que não consigo entender nas gravações e também checar a escrita e o significado. Às vezes consulto colegas para me explicar termos que não encontro em lugar nenhum.

\section{REVER: É possivel fazer a pergunta em inglês?}

BES: Não. Não é possível entrevistar em inglês. Eu penso que quando você fala sobre religião, deve falar na sua própria língua, utilizando-se de termos familiares. 
REVER: A partir das palestras e das aulas que você ministrou no Brasil, como você descreve o alunado brasileiro?

BES: Eu ministrei cursos para diferentes públicos. Em Recife, por exemplo, eram estudantes universitários, alguns pós-graduados, membros do staff e profissionais de ciências aplicadas nas áreas de Psicologia e Psiquiatria. O curso teria a duração de três horas por dia no período da tarde, durante uma semana, só para mim. A audiência estava mais interessada na terapia de saúde mental e não em teorização, harmonização ou em debates. Tive que mudar a apresentação que havia preparado para me concentrar mais naquilo que eles estavam interessados em ouvir, ou seja, o modo como a possessão e o transe impactam a terapia de saúde mental. E as pessoas vieram, começaram a falar e ficou uma atmosfera barulhenta. Mesmo com o microfone, estava difícil para mim. Parecia que eu estava falando para uma barreira de ruídos. Isso foi uma experiência negativa. Já em outras partes do Brasil, no Departamento de Antropologia, como em Florianópolis e Porto Alegre, foi interessante falar das minhas experiências e as pessoas faziam perguntas interessantes. Dei uma preleção por mais de uma hora e depois tive mais uma hora de perguntas. Foi interessante e algumas perguntas foram até desafiadoras, de um nível relativamente bom. Em Londrina, no Departamento das Ciências Sociais, as questōes foram mais básicas. Eles queriam saber mais sobre os detalhes que apareciam nos slides e não sobre as ideias. E depois do debate recebi algumas questôes escritas que também eram de um nível relativamente bom. Em São Paulo fiz uma comunicação na Universidade de São Paulo, infelizmente, durante uma greve. Não havia muitas pessoas, não passavam de vinte. Mas não foi tão ruim. Foi sobre Antropologia. Eu acho que o nível intelectual dos estudantes de Antropologia no Brasil é similar ao da Europa.

REVER: Quais os seus planos para ofuturo e o que você pretende fazer com o material pesquisado no Brasil?

BES: Minha primeira oportunidade será em uma conferência da International Association for The History of Religions (IAHR) em Toronto, quando organizarei uma mesa-redonda com o tema Mente, Corpo e Religião. Essa será minha oportunidade de apresentar algumas das minhas ideias. Também fui convidada a escrever um capítulo de um livro sobre mediunidade, mas antes disso vou escrever sobre minha experiência em Porto Rico. Mas o trabalho final mesmo, como resultado da minha pesquisa realizada aqui no Brasil, será uma monografia. 